\title{
Samsun ve Bafra Yağış Verilerinin Trend Analizi
}

\author{
Büşra Korkmaz ${ }^{1}$, Bahtiyar Efe ${ }^{1 *}$ \\ ${ }^{1}$ Samsun Üniversitesi, Havacılık ve Uzay Bilimleri Fakültesi, Meteoroloji Mühendisliği Bölümü, Samsun, Türkiye, (ORCID: 0000-0002-6666-987X), \\ busrakorkmaz930@gmail.com \\ 1* Samsun Üniversitesi, Havacılık ve Uzay Bilimleri Fakültesi, Meteoroloji Mühendisliği Bölümü, Samsun, Türkiye (ORCID: 0000-0001-5604-7068), \\ bahtiyar.efe@samsun.edu.tr
}

(Illk Geliş Tarihi 20 Şubat 2021 ve Kabul Tarihi 20 Nisan 2021)

(DOI: 10.31590/ejosat.883770)

\begin{abstract}
ATIF/REFERENCE: Korkmaz, B. \& Efe, B. (2021). Samsun ve Bafra Yă̆ı̧ Verilerinin Trend Analizi. Avrupa Bilim ve Teknoloji Dergisi, (23), 844-850.

$\ddot{O} \mathbf{z}$

Ülkemizin iklim değişikliğinden kısa veya uzun vadede etkilenebileceği düşünülmektedir. Bu çalışmada iklim değişikliği için çok önemli bir değişken olan toplam yağış miktarı yıllık, mevsimlik ve aylık olarak incelenmiştir. Çalışma alanı Samsun İli olarak seçilmiş, Samsun ve Bafra meteoroloji istasyonlarının 1990-2019 yılları arasındaki verileri kullanılmıştır. Çalışmanın temel amacı, yağışın trendindeki değişimi Mann-Kendall (MK) Testi ve Şen Yenilikçi Trend Testi (ŞYTT) ile analiz etmektir. Uygulanan testler sonucunda Samsun İstasyonu'nda yıllık toplam yağışta istatistiksel olarak anlamlı olmayan bir artış görülürken, Bafra İstasyonunda azalma görülmektedir. Mevsimlik toplam yağışta ise kış mevsiminde Samsun İstasyonu'nda $\alpha=0.05$ seviyesinde, Bafra İstasyonu'nda $\alpha=0.1$ seviyesinde azalan bir trend olduğu görülmektedir. Samsun İstasyonu'nda diğer mevsimlerde artış görülürken, Bafra İstasyonu'nda yalnızca yaz mevsimde artı̧̧ görülmektedir. Aylık toplam yağışlarda ise Samsun İstasyonu'nda Ocak, Mart, Haziran, Temmuz ve Aralık aylarında artan; diğer aylarda azalan trend vardır. Bafra İstasyonu'nda ise Mart, Temmuz, Ağustos ve Aralık aylarında artan; diğer aylarda azalan bir trend vardır.
\end{abstract}

Anahtar Kelimeler: Mann-Kendall Testi (MK), Şen Yenilikçi Trend Testi (ŞYTT), Samsun, Yağış.

\section{Trend Analysis of Samsun and Bafra Precipitation Data}

\begin{abstract}
It is thought that our country may be affected by climate change in the short or long term. In this study, the total amount of precipitation, which is a very important variable for climate change, has been examined monthly, seasonally and annually. The study area was chosen as Samsun province, and data of Samsun and Bafra stations between 1990-2019 were used. The main purpose of the study is to analyze the change in the trend of precipitation and two trend tests were used for this: Mann-Kendall (MK) test and Şen Innovative Trend Test (ŞYTT). As a result of the tests applied, a statistically insignificant increase was observed in the annual total precipitation at Samsun Station, while a decrease was observed at Bafra Station. It is observed that there is a decreasing trend in total seasonal precipitation at the level of $\alpha=0.05$ at Samsun station and $\alpha=0.1$ at the Bafra Station in winter. While there is an increase in Samsun Station in other seasons, at Bafra station it is seen only in summer season. Monthly total precipitation increased in Samsun Station in January, March, June, July and December; there is a decreasing trend in other months. At Bafra Station, on the other hand, it increased in March, July, August and December; there is a decreasing trend in other months.
\end{abstract}

Keywords: Mann - Kendall Test, Şen Innovative Trend Test, Samsun, Precipitation.

\footnotetext{
*Sorumlu Yazar: bahtiyar.efe@samsun.edu.tr
} 


\section{Giriş}

Yağış canlı yaşamı ve meteoroloji açısından oldukça önemli bir değişkendir. Ayrıca yağışın miktarı ve rejimindeki değişim iklim değişikliğine yol açabilmektedir. Bu çalışmada, sınırlı bir alan için (Samsun İli) ve tek bir meteorolojik değişken (yağış) üzerinden iklim değişikliğine dair bilgi edinilmeye çalışılmıştır. Eksik ve/veya düzensiz yağış, kuraklık ve/veya taşkınlara neden olabilmektedir.

Türkeş, Koç ve Sarıș (2007) Türkiye geneli için yaptıkları bir çalışmada 111 istasyonun 40 ila 73 yıl arasında değişen yağış verilerini kullanmışlardır. Çalışmalarında Mann-Kendall (M-K) sıra ilişkisi katsayısı yöntemini kullanmışlardır. Bu çalışmada hem toplam yağışı hem de yağış yoğunluğunu mevsimlik ve yıllık olarak incelemişlerdir. Yaptıkları çalışmalar sonucunda 0.05 anlamlılık düzeyinde sonuçlar elde etmişlerdir. Kış mevsimi yağış sonuçlarına göre 27 istasyonda anlamlı azalma yaşanırken yalnızca 1 istasyonda anlamlı artış yaşanmıştır. Kış mevsimi yağış yoğunluğu sonuçlarına göre ise 38 istasyonda anlamlı azalma yaşanırken yalnızca 5 istasyonda anlamlı artış yaşanmıştır. İlkbahar mevsimi yağışlarında anlamlı bir artış görülmekle birlikte yağış yoğunluğunda kuvvetli olmayan bir azalma meydana geldiği sonucuna varmışlardır. Yaz ve sonbahar mevsimlerinde ise yağışlarda artış, yağış yoğunluğunda azalma eğilimi olduğunu belirtmişlerdir. Yıllık değerlendirme sonucunda ise yağışta ve yağış yoğunluğunda genel olarak bir azalma eğilimi olduğu ancak bu azalmanın yağış yoğunluğunda daha fazla olduğunu dile getirmişlerdir.

Sütgibi (2015) yapmış olduğu bir çalışmada Büyük Menderes Havzası'nda bulunan illerin uzun yıllar toplam yağışındaki değişimi incelemiştir. $\mathrm{Bu}$ çalışmayı yaparken Afyon, Aydın, Denizli ve Uşak İl merkezlerinde bulunan meteoroloji istasyonlarından aldıkları verileri kullanmıştır. Afyon İli için 83 yıllık (1930-2012), diğer iller için 53 y1llık (1960-2012) meteoroloji verileri kullanmıştır. Çalışmasında yıllar ve mevsimler arası toplam yağıştaki değişiklikleri ve bu değişikliklerin eğilimini, yağışlı gün sayılarını ve yağış anomalilerini incelemiştir. Çalışmasında Mann-Kendal sıra ilişkisi katsayısını kullanmıştır. Çalışma sonucunda Afyon ilindeki yağışlarda yıllar içerisinde bir azalma; Aydın, Denizli ve Uşak İllerinde ise kuvvetli olmayan bir artış olduğunu söylemiştir. Bu azalış veya artışların istatistiksel olarak anlamlı olmadığını da dile getirmiştir. Yağışlı gün sayılarında ise Aydın, Denizli ve Uşak illerinde azalma; Afyon ilinde ise artış olduğunu ve yine istatistiksel olarak anlamlı olmadığını dile getirmiştir. Yine mevsimler için de artış veya azalışları söylemiş ve istatistiksel olarak anlamlı olmadığını söylemiştir.

Coşkun (2020) Van Gölü kapalı havzasının yağış analizini yapmıştır. Çalışmasında bu havzada bulunan Van-Bölge, Muradiye, Erciş, Gevaş, Özalp, Tatvan ve Ahlat İstasyonlarının 1964-2017 yılları arasındaki meteorolojik verilerini kullanmıştır. Çalışmasını yaparken Mann-Kendall, Spearman Rho ve Şen testlerini kullanmıştır. Mann-Kendall ve Spearman Rho eğilim testlerinin sonuçlarına göre Ahlat ve Gevaş İstasyonlarında negatif eğilim olduğunu bu sonuçların istatistiksel açıdan anlamlı olduğunu bulmuştur. Erciş, Özalp, Tatvan ve Muradiye İstasyonlarında negatif, Van-Bölge İstasyonu'nda pozitif eğilim olduğunu ancak bu sonuçların istatistiksel açıdan anlamlı olmadığını bulmuştur. Yaptığı bu çalışma 0.05 anlamlılık düzeyindedir. Ayrıca Şen trend analizi testini uyguladığı Ahlat ve Gevaş istasyonlarında anlamlı bir azalma olduğunu söylemiştir.
Diğer istasyonlardaki artış veya azalışlarında anlamlı olmadı̆̆ını söylemiştir.

Daha önce ülkemizde il ve havza bazında veya Türkiye genelinde çalışmalar yapılmıştır. Bunlardan bazıları şunlardır: Türkeş, Koç ve Sarış (2007); Karabulut ve Cosun (2009); Sütgibi (2015); Zeybekoğlu ve Karahan (2017); Demir ve ark (2017); Polat ve Sunkar (2017); Soydan ve ark. (2016); Coşkun (2020).

$\mathrm{Bu}$ çalışmanın temel amacı Mann-Kendall (MK) ve Şen Yenilikçi Trend Testi (ŞYTT) kullanılarak Samsun İli'nde yer alan ve uzun yıllara ait gözlem verisi olan gözlem istasyonlarında toplam yağışın trendini incelemektir. Bunun için Samsun İli’nde bulunun Samsun ve Bafra İstasyonu'ndan alınan veriler ile 19902019 yılları arasındaki aylık, mevsimlik, yıllık toplam yağışın trend analizini yapmaktır.

Çalışmanın devamında sırasıyla materyal ve yöntem, trend analizi ve sonuç kısımları bulunmaktadır.

\section{Materyal ve Metot}

Yapılan çalışmada Samsun ve Bafra istasyonunda 1990 2019 yıllarına ait günlük toplam yağış verileri kullanılarak, aylık, mevsimlik ve yıllık toplam yağışların trend analizi yapılacaktır.

\subsection{Materyal}

Samsun İli Orta Karadeniz'in kıyı şeridinde Kızılırmak (Bafra) ve Yeşilırmak (Çarşamba) nehirlerinin oluşturduğu deltaların arasında yer alır. Samsun İli $9.579 \mathrm{~km} 2$ ‘lik bir yüz ölçümüne sahiptir. Coğrafi konum olarak $40^{\circ} 50^{\prime}-41^{\circ} 51^{\prime}$ kuzey enlemleri, $37^{\circ} 08^{\prime}$ ve $34^{\circ} 25^{\prime}$ doğu boylamları arasında yer almaktadır. Samsun İli'nin kuzeyinde Karadeniz bulunurken; doğusunda Ordu, batısında Sinop, güneyinde ise Tokat, Amasya ve Çorum illeri vardır (Tarım ve Orman Bölge Müdürlüğü Çalışma Raporu, 2019).

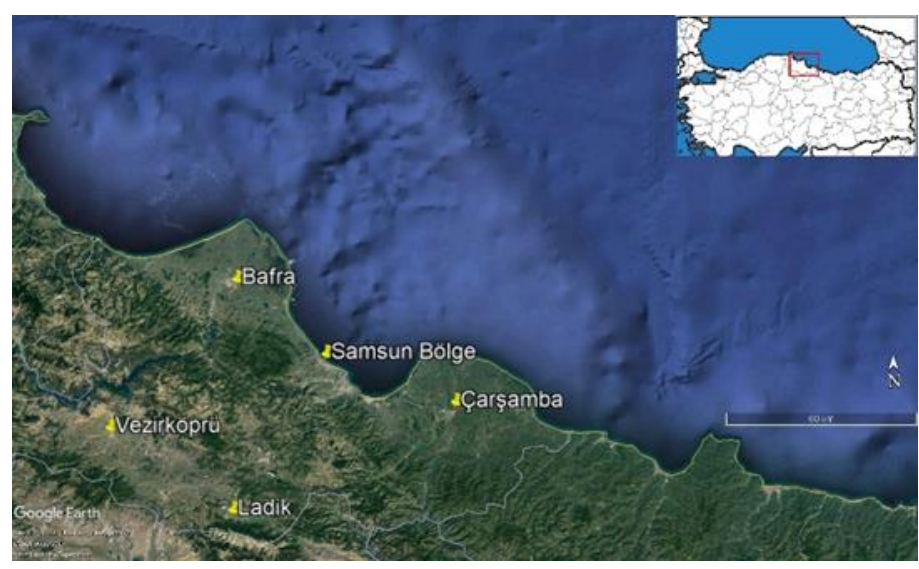

Şekil 1 Çalışma Alanı (Kaynak: Google Earth, 2021).

Samsun İli'nin yağış verisini noktasal ve zamansal incelemek için Samsun İli'nde bulunan 2 meteoroloji istasyonundaki (Samsun Bölge ve Bafra meteoroloji istasyonları) yağış verileri kullanılmıştır ve bu veriler Meteoroloji Genel Müdürlüğü (MGM)'den temin edilmiştir. Bundan sonra Samsun Bölge Meteoroloji İstasyonu yerine, Samsun İstasyonu; Bafra Meteoroloji İstasyonu yerine Bafra İstasyonu ifadesi kullanılacaktır. Yapılan çalışmada Samsun ve Bafra İstasyonu'nda 1990 - 2019 yıllarına ait günlük toplam yağış verileri kullanıldı. 


\subsection{Metot}

\subsubsection{Mann-Kendall Testi}

Mann-Kendall testi (Mann, 1945; Kendall, 1975) Kendall's Tau testinin özel bir uygulamasıdır ve parametrik olmayan bir testtir. Bu test verilerde trend bulmak için kullanılır. Bu yöntemde verilerin değerlerinden çok sıra numaraları önemlidir. Zamana göre sıralanmış $\left(\mathrm{x}_{1}, \mathrm{x}_{2}, \ldots, \mathrm{x}_{\mathrm{n}}\right)$ serileri $\mathrm{H}_{0}$ hipotezine göre zamandan bağımsız ve benzer dağılım gösteren rastgele değişkenlerdir. $H_{1}$ alternatif hipotezine göre ise $(k \neq j)$ ve $n \geq k, j$ ( $n$, veri kayıt uzunluğu) olmak üzere seride $x_{k}$ ve $x_{j}$ ardışık data değerlerinin dağılımı benzer değildir. Yani seride lineer bir trend vardir.

Mann-Kendall testinin $\mathrm{S}$ istatistiği aşağıdaki şekilde hesaplanır.

$$
\begin{aligned}
& \mathrm{S}=\sum_{k=1}^{n-1} \sum_{j=k+1}^{n} \operatorname{sgn}\left(\mathrm{x}_{\mathrm{j}}-\mathrm{x}_{\mathrm{k}}\right) \\
& \operatorname{Sgn}\left(\mathrm{x}_{\mathrm{j}}-\mathrm{x}_{\mathrm{k}}\right)=\left\{\begin{array}{c}
+1 \text { Ĕ } \operatorname{ger}(\mathrm{xj}-\mathrm{xk})>0 \\
0 \text { Ĕger }(\mathrm{xj}-\mathrm{xk})=0 \\
-1 \operatorname{Eğer}(\mathrm{xj}-\mathrm{xk})<0
\end{array}\right.
\end{aligned}
$$

Normal bir dağılıma sahip olan ve ortalaması sıfır olan test istatistiği S'nin varyansı aşağıdaki gibi hesaplanır.

$$
\operatorname{Var}(\mathrm{S})=\frac{n(n-1)(2 n+5)}{18}
$$

Eğer verilerde benzer değerler varsa varyans hesabı aşağıdaki şekilde yapılır.

$$
\operatorname{Var}(\mathrm{S})=\frac{n(n-1)(2 n+5)-\sum_{t} t(t-1)(2 t+5)}{18}
$$

Daha sonra standart normal değişkeni $\mathrm{z}$ aşağıdaki gibi hesaplanır ve kritik z değeri ile karşılaştırılır. İfadede yer alan 1 sayıları süreklilik düzeltme birimleridir.z $=\left\{\begin{array}{c}\frac{s-1}{\sqrt{\operatorname{Var}(S)}} E \breve{\mathrm{g}} \text { er } S>0 \\ 0 \quad E \breve{\mathrm{g}} \text { er } S=0 \\ \frac{S+1}{\sqrt{\operatorname{Var(S)}}} E \breve{\mathrm{g}} \text { er } S<0\end{array}\right.$

Daha sonra standart normal dağılım tablolarından bulduğumuz z değerine karşılık gelen değer bulunur ve bu değer 2 ile çarpılır. Hesaplanan değer belirlenen $\alpha$ anlamlılık seviyesinden $(\alpha=0.01, \alpha=0.05$ ve $\alpha=0.1)$ küçük ve eşit ise $H_{0}$ hipotezi kabul edilmekte yani trend var denilmektedir, aksi halde reddedilmektedir. Mann-Kendall test istatistiği S değeri negatif ise azalan, pozitif ise artan bir trendin varlığını gösterir.

\subsection{2. Şen Yenilikçi Trend Testi}

Elimizde bulunan tarihlerine göre sıralanmış veri serisi ortadan ikiye olacak şekilde ayrılır. Daha sonra her iki alt seri de kendi içerisinde küçükten büyüğe doğru sıralanır. İlk alt seride $\left(\mathrm{x}_{\mathrm{i}}\right)$ bulunan veriler $\mathrm{x}$ eksenine, ikinci alt seride $\left(\mathrm{x}_{\mathrm{j}}\right)$ bulunan veriler $\mathrm{y}$ eksenine yerleştirilir (Şekil 2). Veriler 1:1 doğrusu üzerinde ise trend yok demektir. Veriler üst üçgende toplanmış ise artan bir trend, alt üçgende toplanmış ise azalan bir trend olduğu sonucuna varılır. Değer 1:1 doğrusundan yani trendsizlik eğrisinden ne kadar uzaklaşırsa şiddeti de o kadar artar (Şen, 2012). Bizim çalışmamızda X ekseninde 1990 - 2004 yılları arası toplam yağış değerleri, Y ekseninde ise 2005 - 2019 yılları arası toplam yağış değerleri bulunmaktadır.

Çalışmada yapılan hesaplamalar temel R ( $\mathrm{R}$ Core team, 2018) paketleri, tidyverse (Wickham, 2017) paketi kullanılarak yapılmıştır. ŞYTT grafikleri ise ggplot (Wickham, 2016) paketi kullanılarak hazırlanmıştır.

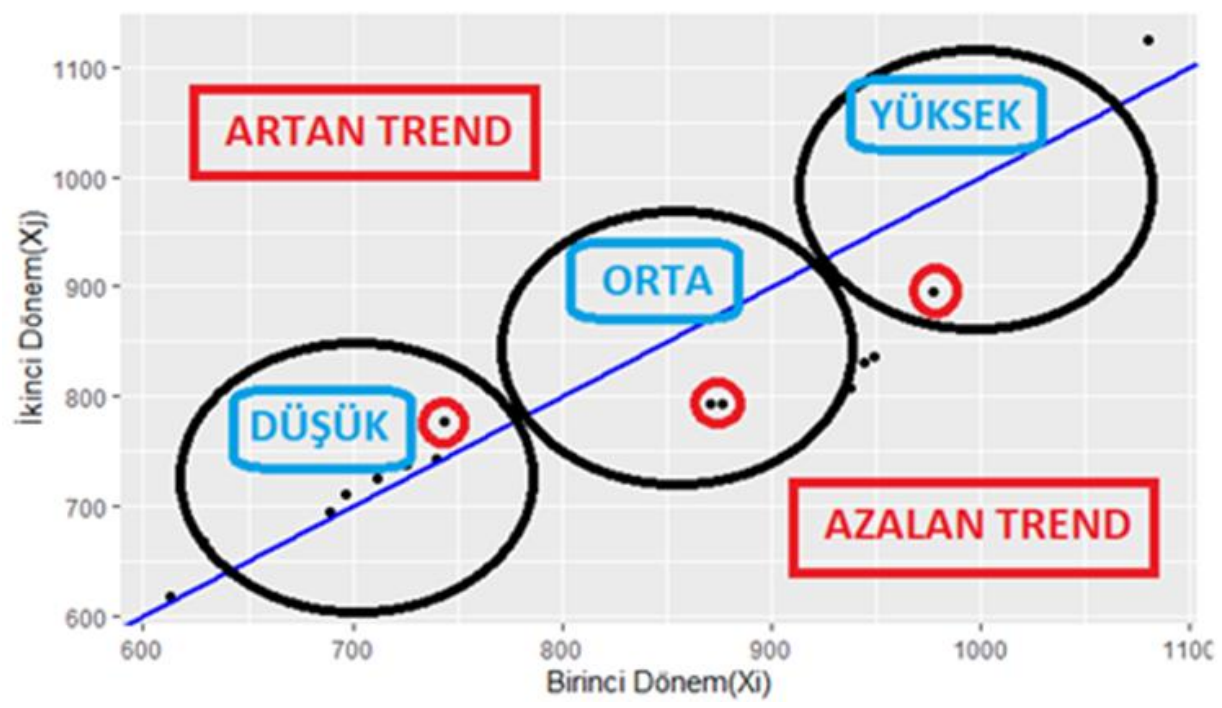

Şekil 2 Şen Yenilikçi Trend Testi Örneği.

\section{Araştırma Sonuçları ve Trend Analizi}

Bu kısımda Samsun ve Bafra İstasyonlarının 1990 - 2019 yılları arasındaki yağış verilerindeki trend detaylı olarak anlatılacaktır.

\subsection{Samsun İstasyonu}

\subsubsection{Samsun İstasyonu Yıllık Trend Analizi}

Samsun İstasyonu'na ait 1990-2019 yılları arasında yıllık toplam yağışların ortalaması 729 mm'dir. 2014 yılı $603.7 \mathrm{~mm}$ ile 
toplam yağışın en düşük olduğu yıl olurken, 2012 yılı $999.1 \mathrm{~mm}$ ile toplam yağışın en yüksek olduğu yıl olmuştur. MK uygulandığında $\mathrm{p}$ değeri 0.239 olup, istatistiksel olarak anlamlı olmayan artan bir trend vardır. ŞYTT sonuçlarına bakıldığı zaman, düşük değerler azalan trend bölgesinde başlamış, sonra artan trend bölgesine geçmiştir. Orta değerler tamamen artan trend bölgesindedir. Yüksek değerler ise artan trend bölgesinde başlamış, daha sonra azalan trend bölgesine geçmiş daha sonra tekrar artan trend bölgesine geçmiştir.

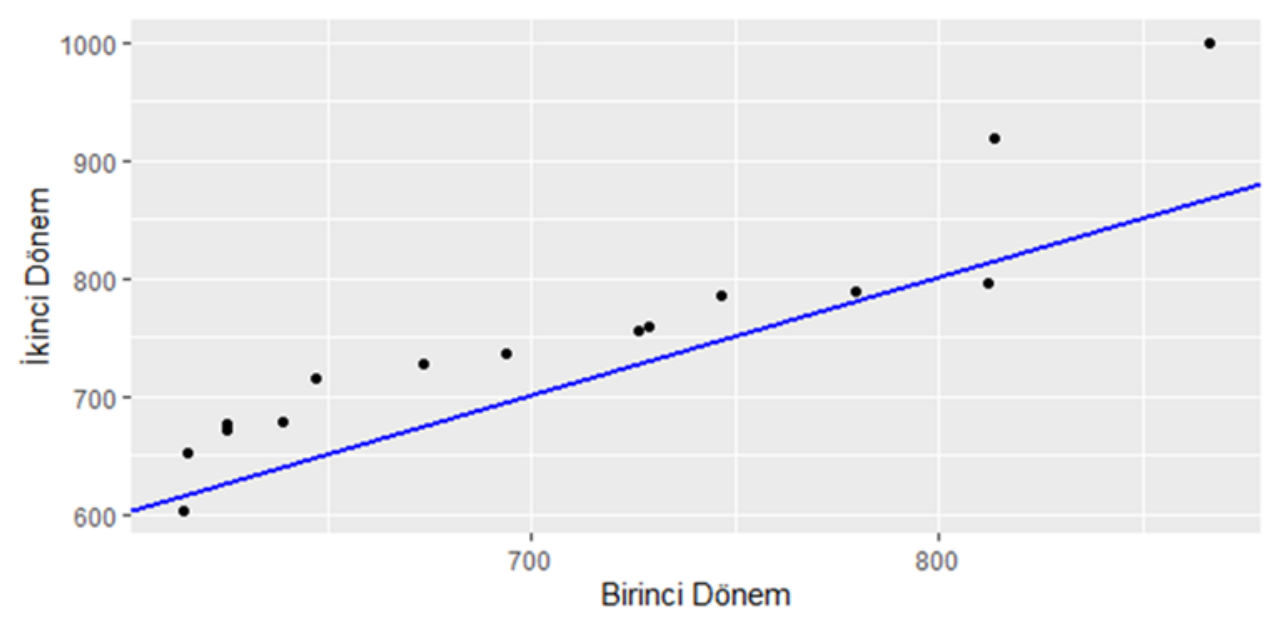

Şekil 3 Samsun İstasyonu 1990 - 2019 yılları arası yıllık toplam yă̆ış ŞYTT grafiği..

\subsubsection{Samsun İstasyonu Mevsimlik Trend Analizi}

Mevsimlik toplam yağışta kış, ilkbahar ve yaz mevsimlerinde MK testine göre artan bir trend vardır. Bunlardan yalnızca kış mevsimi $\alpha=0.05$ seviyesinde anlamlıdır. Aynı mevsimlerin ŞYTT sonuçlarına bakıldığı zaman kış mevsimindeki artış aynı şekilde görülmektedir. Düşük değerlerin bir kısmı azalan trend bölgesinde iken, orta ve yüksek değerlerin tamamı artan trend bölgesindedir. İlkbahar ve yaz mevsimlerinde ise küçük ve orta değerler trendsizlik çizgisinin etrafında dağılım gösterirken, en büyük yüksek değerlerin artan trend bölgesinde olduğu görülmektedir. Sonbahar mevsiminde her iki trend testine göre de azalma vardır. Bu azalma MK testine göre istatistiksel olarak anlamlı değildir. Şen testine göre en küçük iki değer hariç diğer değerlerin hepsi ya azalan trend bölgesindedir ya da trendsizlik çizgisi üzerindedir.

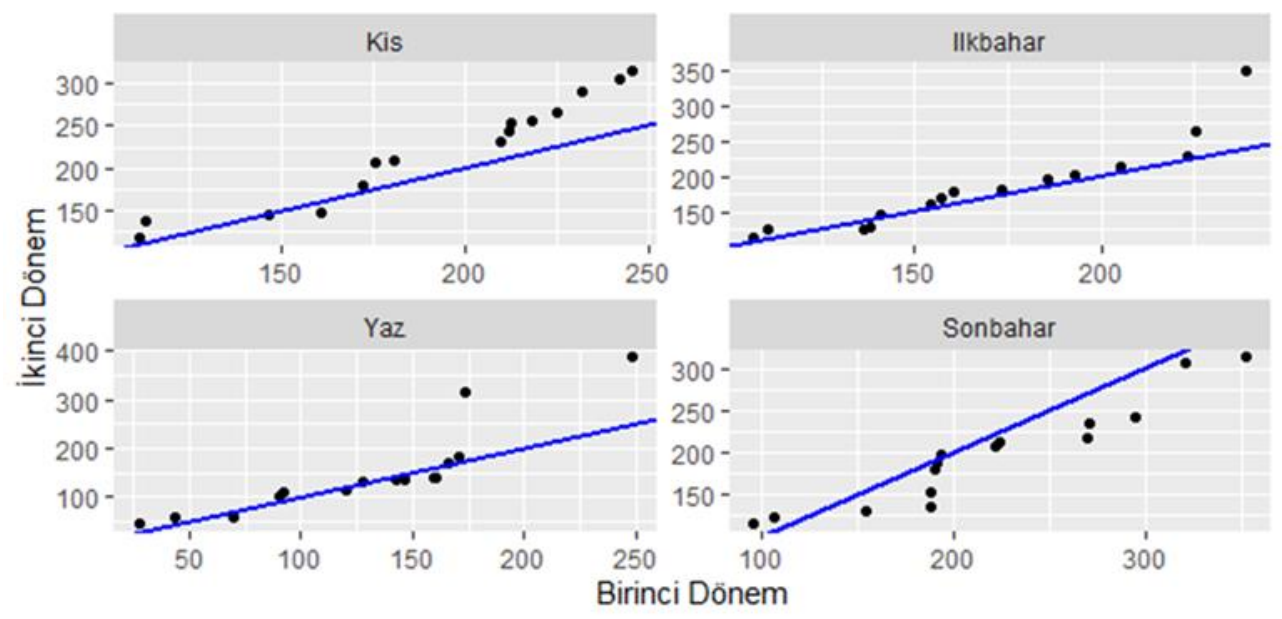

Şekil 4 Samsun İstasyonu 1990 - 2019 yılları arası mevsimlik toplam yağış ŞYTT grafiği.

\subsubsection{Samsun İstasyonu Aylık Trend Analizi}

Aylık toplam yağ 1 şta MK trend testine göre Ocak $(\alpha=0.05)$ ve Mart $(\alpha=0.1)$ aylarında istatistik olarak anlamlı artan trend vardır. Haziran, Temmuz ve Aralık aylarında artan; diğer aylarda azalan trend vardır. Bunlardan yalnızca Ocak ayı $\alpha=0.05$ ve Mart ayı $\alpha=0.1$ seviyesinde anlamlıdır. Ocak ayında ŞYTT incelendiğinde, düşük değerler azalan trend bölgesinde başlamış, sonra artan trend bölgesine geçmiştir. Orta ve yüksek değerler ise, tamamen artan trend bölgesindedir. Mart ayında ise, düşük değerler artan trend bölgesinde başlamış sonra trendsizlik çizgisine yaklaşmış sonra tekrar artan trend bölgesine geçmiştir. Orta değerlerden bir tanesi trendsizlik çizgisine yakın iken diğerleri artan trend bölgesindedir. Yüksek değerlerin ise tamamı artan trend bölgesindedir. Mayıs ve Temmuz aylarında neredeyse tüm veriler trendsizlik doğrusu üzerindedir. Diğer aylarda ŞYTT değerlerinde belirli bir örüntü yoktur. 

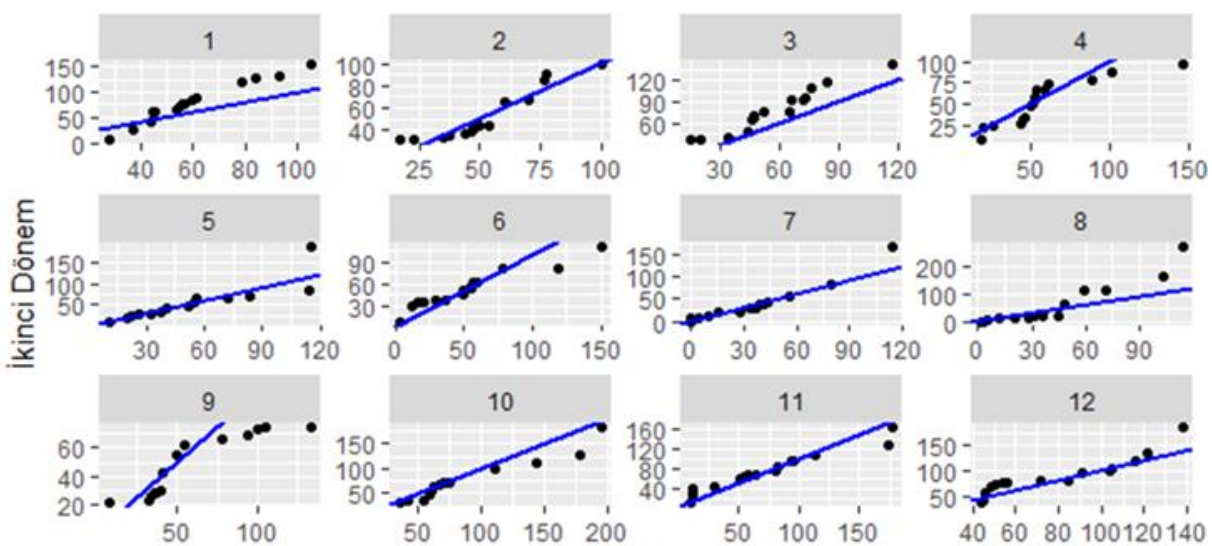

Şekil 4 Samsun İstasyonu 1990 - 2019 yılları arası aylık toplam yă̆ı̧s ŞYTT grafiği.

\subsection{Bafra İstasyonu}

\subsubsection{Bafra İstasyonu Yıllık Trend Analizi}

Bafra İstasyonu'na ait 1990-2019 y1lları arasında yıllık toplam yağışların ortalaması 749 mm'dir. 2014 yılı $511.6 \mathrm{~mm}$ ile toplam yağışın en düşük olduğu yıl olurken, 2004 yılı 1124.7 mm ile toplam yağışın en yüksek olduğu yıl olmuştur. MK testi uygulandığında yıllık toplam yağışta istatistiksel olarak anlamlı olmayan azalan bir trend olduğu görülmektedir. ŞYTT sonuçlarına bakıldığında, düşük ve orta değerlerin azalan trend bölgesinde olduğu görülmektedir. Yüksek değerlerin ise azalan trend bölgesinde başlayıp, en büyük değer azalan trend bölgesindedir.

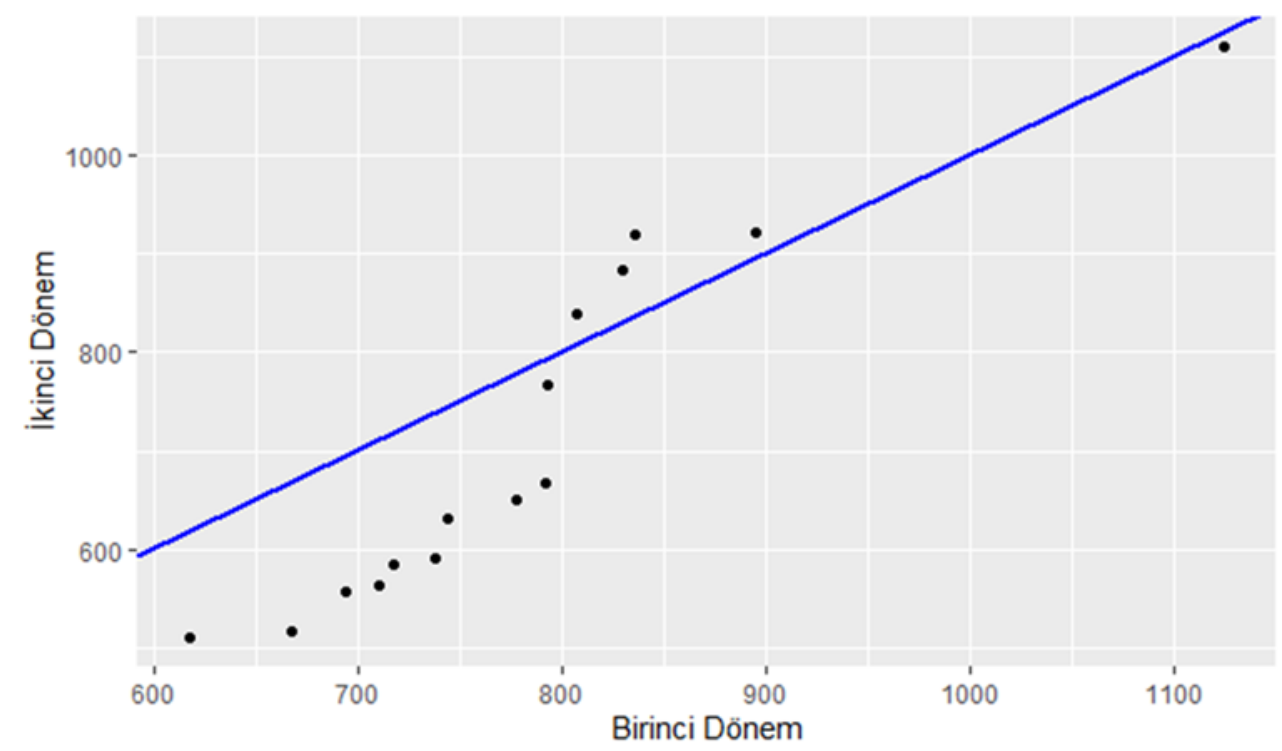

Şekil 5 Bafra İstasyonu 1990 - 2019 yılları arası yıllık toplam yă̆ış ŞYTT grafiği.

\subsubsection{Bafra İstasyonu Mevsimlik Trend Analizi}

Mevsimlik toplam yağışta MK ya göre, sonbahar mevsiminde $\alpha=0.1$ anlamlılık seviyesinde azalan trend vardır. Diğer mevsimlerde anlamlı bir artış ya da azalış yoktur. ŞYTT'ye göre sonbaharda bütün değerler azalan trend bölgesindedir. Kış mevsiminde, yüksek değerlerdeki tek bir değer artan trend bölgesinde diğer değerler ise ya trendsizlik doğrusu üzerinde ya da azalan trend bölgesindedir. İlkbahar mevsiminde, ilk iki değer artan trend bölgesinde diğerleri azalan trend bölgesindedir. Yaz mevsiminde, düşük değerler azalan trend bölgesinde başlamış, sonra trendsizlik doğrusu üzerinde devam etmiştir. Orta değerler artan trend bölgesindedir. Yüksek değerlerden ise sadece bir tanesi azalan trend bölgesinde olup diğerleri artan trend bölgesindedir. 


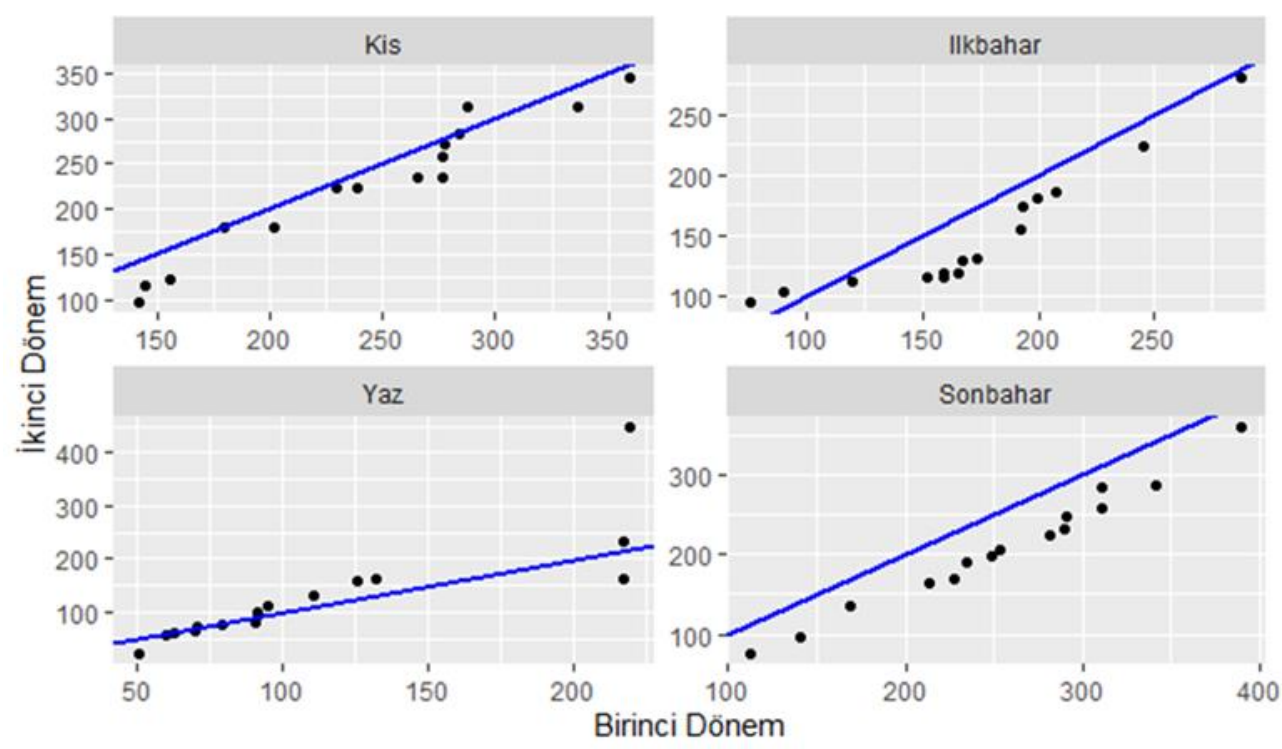

Şekil 6 Bafra İstasyonu 1990 - 2019 yılları arası mevsimlik toplam yağıs ŞYTT grafiği.

\subsubsection{Bafra İstasyonu Aylık Trend Analizi}

Aylık toplam yă̆ışta MK trend testine göre de Mart, Temmuz, Ağustos ve Aralık aylarında artan; diğer aylarda azalan bir trend vardır. $\mathrm{Bu}$ trendler MK testine göre istatistiksel olarak anlamlı değildir. ŞYTT 'ye göre Şubat ayında en düşü iki değer ve en yüksek değer hariç diğer tüm değerler azalan trend bölgesindedir. Nisan ayında orta değerler trendsizlik çizgisine yakın olarak azalan trend bölgesinde, diğer değerler ise azalan trend bölgesindedir. Temmuz ayında düşük değerler ve orta değerlerin küçük olanları trendsizlik doğrusu etrafında salınırken, diğer değerler artan trend bölgesindedir. Ağustos ayında sadece en yüksek değer hariç diğerleri trendsizlik çizgisi etrafında salınmaktadır. Eylül ayında ise, en düşük değer trendsizlik çizgisi üzerinde yer almakta olup, diğer değerlerin hepsi azalan trend bölgesindedir.
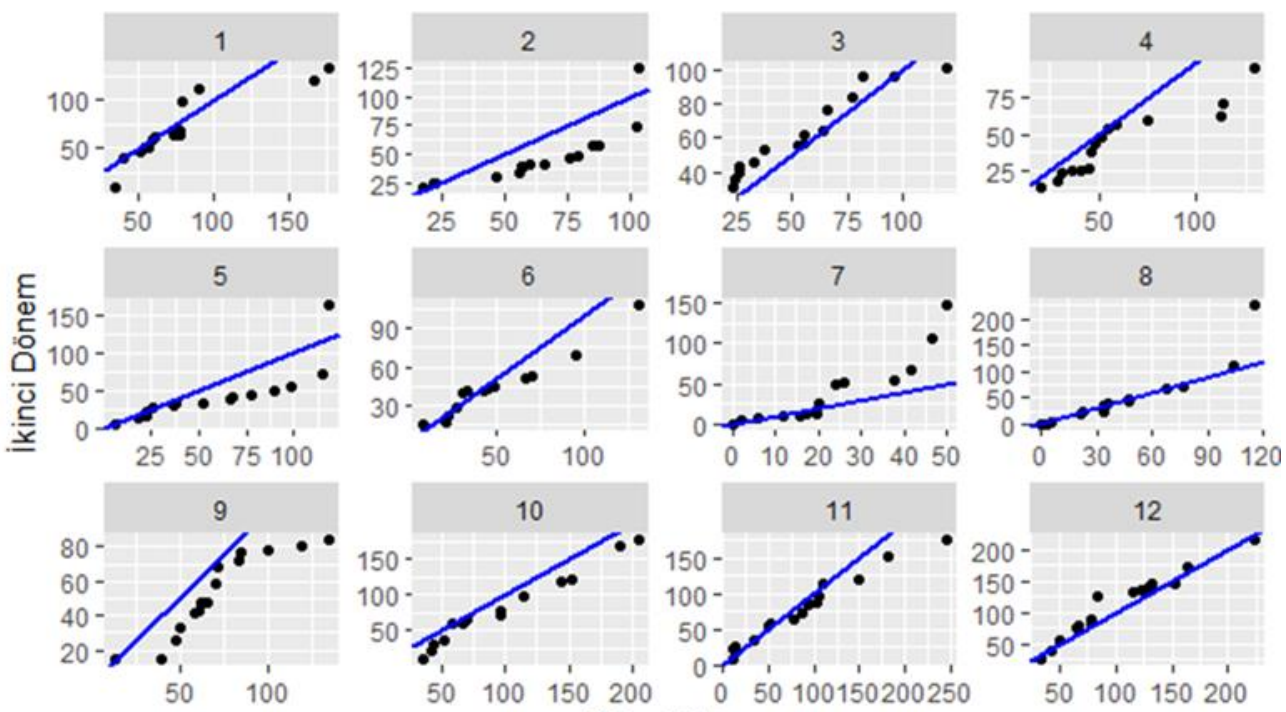

Şekil 7 Bafra İstasyonu 1990 - 2019 yılları arası aylık toplam yağış ŞYTT grafiği.

\section{Sonuç}

Çalışmada Samsun İli’nde bulunan Samsun Bölge ve Bafra istasyonlarından alınan, 1990 - 2019 yıllarına ait günlük toplam yağış verileri kullanılmıştır. Daha sonra bu veriler üzerinde MannKendall (MK) ve Şen Yenilikçi Trend Testi (ŞYTT) kullanılarak trend analizi yapılmıştır.
Samsun İstasyonu incelenen dönemde yıllık toplam yağışta her iki trend testi sonucuna göre de istatistiksel olarak anlamlı olmayan artan bir trend olduğu görülmektedir. Mevsimlik toplam yağışta her iki trend testine göre de kış, ilkbahar ve yaz mevsimlerinde artan, sonbahar mevsiminde azalan bir trend vardir. Bunlardan yalnızca kış mevsimi $\alpha=0.05$ seviyesinde anlamlıdır. Aylık toplam yağışta MK trend testine göre Ocak, Mart, Haziran, Temmuz ve Aralık aylarında artan; diğer aylarda azalan trend vardır. Bunlardan yalnızca Ocak ay $\alpha=0.05$ ve Mart ayı $\alpha=0.1$ 
seviyesinde anlamlıdır. ŞYTT sonuçları MK testi sonuçlarını doğrulamamaktadır. Sürekli artan veya sürekli azalan aylar çok azdir.

Bafra İstasyonu incelenen dönemde yıllık toplam yağışta MK testi sonucuna göre istatistiksel olarak anlamlı olmayan azalan bir trend olduğu görülmektedir. ŞYTT sonuçlarına bakıldığında ise yüksek değerlerin daha çok artma trendinde olduğu görülmektedir. Mevsimlik toplam yağışta her iki trend testine göre de kış, ilkbahar ve sonbahar mevsimlerinde azalan; yaz mevsiminde artan bir trend vardır. Bunlardan yalnızca sonbahar mevsimi $\alpha=0.1$ seviyesinde anlamlıdır. Aylık toplam yağışta ise her iki trend testine göre de Mart, Temmuz, Ağustos ve Aralık aylarında artan; diğer aylarda azalan istatistiksel olarak anlamlı olmayan bir trend vardir.

\section{Teşekkür}

Yazarlar, makalede kullanılan veriler için Meteoroloji Genel Müdürlüğü'ne teşekkür eder.

\section{Kaynakça}

Coşkun, S. (2020). Van Gölü Kapalı Havzasında Yağışların Trend Analizi, Mühendislik Bilimleri ve Tasarım Dergisi, 8(2), 521 532.

Demir, A. D., Demir, Y., Şahin, Ü. ve Meral, R. (2017). Bingöl İli’nde Sıcaklık ve Yağışların Trend Analizi ve Tarıma Etkisi, Türk Tarım ve Doğa Bilimleri Dergisi, 4, 284-291.

Google Earth V 7.3.3.7786 (2021). Çalışmada kullanılan istasyonlarin yerleri. Basarsoft 2012. http://www.earth.google.com , 10 Şubat 2021 tarihinde alindi.

Karabulut, M. ve Cosun, F. (2009). Kahramanmaraş İlinde Yağışların Trend Analizi, Coğrafi Bilimler Dergisi, 7, 65-83.

Kendall, M.G., (1975). Rank Correlation Methods. Charles Griffin, London.

Mann, H. B., (1945) Non-parametric Test Against Trend, Econometrika, 13, 245-259.

Polat, P. ve Sunkar, M. (2017). Rize'nin İklim Özellikleri ve Rize Çevresinde Uzun Dönem Sıcaklık ve Yağış Verilerinin Trend Analizleri, Furat Üniversitesi Sosyal Bilimler Dergisi, 24, 123.

R Core Team (2018). R: a language and environment for statistical computing. $\mathrm{R}$ Foundation for Statistical Computing, Vienna. https://www.R-project.org/. adresinden alindi.

Soydan, N. G., Gümüş, V., Şimşek, O., Gerger, R. ve Ağun, B. (2016). Seyhan Havzası Aylık Ortalama Akım ve Yağış Verilerinin Trend Analizi, Dicle Üniversitesi Mühendislik Fakültesi Mühendislik Dergisi, 7, 319-328.

Sütgibi, S. (2015). Büyük Menderes Havzasının Sıcaklık, Yağış ve Akım Değerlerindeki Değişimler ve Eğilimler, Marmara Coğrafya Dergisi, 398-414.

Şen, Z. (2012). Innovative Trend Analysis Methodology. Journal of Hydrological Engineering, 17 (9): 1042-1046.

Tarım ve Orman Bölge Müdürlüğü (2019). Tarım ve Orman Bölge Müdürlüğü Çalışma Raporu.

Türkeş, M., Koç, T. ve Sarış, F. (2007). Türkiye'nin Yağış Toplamı ve Yoğunluğu Dizilerindeki Değişikliklerin ve Eğilimlerin Zamansal ve Alansal Çözümlemesi, Coğrafi Bilimler Dergisi, 5, 57-73.
Wickham H. (2016). ggplot2: elegant graphics for data analysis. Springer, New York http://ggplot2.org adresinden alınd1.

Wickham H. (2017). tidyverse: Easily Install and Load the 'Tidyverse'. R package version 1.2.1. https://CRAN.Rproject.org/package=tidyverse adresinden alınd1.

Zeybekoğlu, U. ve Karahan, H. (2018). Standart Süreli Yağış Şiddetlerinin Eğilim Analizi Yöntemleriyle İncelenmesi, Pamukkale Üniversitesi Mühendislik Bilimleri Dergisi, 24, 974-1004. 